\title{
Natives helping foreigners? The effect of inoculation of poplar with patagonian beneficial microorganisms
}

\author{
María Cecilia Mestre $^{1^{*}}$, Mario J. Pastorino ${ }^{2,3}$, Alejandro G. Aparicio ${ }^{2}$, Sonia B. Fontenla ${ }^{1}$ \\ ${ }^{1}$ Laboratorio de Microbiología Aplicada y Biotecnología, Centro Regional Universitario Bariloche (CRUB), \\ UNCO- IPATEC (Universidad Nacional del Comahue-CONICET). Quintral 1250, Bariloche (8400), Río \\ Negro, Argentina. ${ }^{2}$ Unidad de Genética Ecológica y Mejoramiento Forestal, Instituto Nacional de Tecnología \\ Agropecuaria, Modesta Victoria 4450 CC 277, 8400 Bariloche, Río Negro, Argentina. ${ }^{3}$ Centro Científico \\ Tecnológico Patagonia Norte (CONICET), Av. De los Pioneros 2350, Bariloche (8400), Río Negro, Argentina. \\ *Corresponding author: mariaceciliamestre@gmail.com
}

\begin{abstract}
Inoculation with microorganisms represents an opportunity to enhance tree production, directly affecting plant growth or survival at planting. The aim of the present study was to evaluate the effect of mixed inoculation with native mycorrhizae, two yeasts and one endophytic bacterium, on the growth of two poplar clones commonly used in Patagonia, Argentina. Yeasts and bacteria were selected base on their ability to produce IAA and siderophores, as well as P solubilization in-vitro. A greenhouse trial was performed using hardwood cuttings of Populus nigra 'Italica' and Populus trichocarpa 'SP1456'. Only yeasts modified growth traits, in a host-related response: Tausonia pullulans reduced the root/shoot ratio in P. nigra, and Candida saitoana and increased shoot dry biomass in P. trichocarpa. All plants presented arbuscular mycorrhizal colonization but ectomycorrhizae were absent. Two types of arbuscular mycorrhizal colonization were observed, one of them similar to Glomus tenue. We found a tendency for a higher percentage of arbuscular mycorrhizal colonization when plants were inoculated with $T$. pullulans. The used of native yeast along with mycorrhizal inocula appears to be a promising tool to improve poplar forestry.
\end{abstract}

Keywords: Mycorrhizae symbiosis, soil yeasts, endophytic bacteria 


\section{Introduction}

Populus is one of the main forest tree genera cultivated in Argentina. In particular, it is an important economic resource in the Río Negro Valley in Patagonia, where poplars occupy some 2100 ha of irrigated area (Serventi and García, 2004) and form more than 12,000 km of windbreaks (Serventi, 2011), contributing to improving environmental conditions for apple and pear production and supplying the local wood industry. Poplars in Patagonia however, are not restricted to the Río Negro Valley. They have been closely related to human settlement everywhere, and windbreaks are used to provide shelter to houses, local crops and livestock, reducing the effects of the constant and harsh Patagonian winds. The first utilized and most widespread clone in Patagonia is $P$. nigra 'Italica' (Serventi, 2011), a male clone selected in Lombardy in the $17^{\text {th }}$ century and introduced in southern South America during colonial times. On the other hand, among the promising clones still in evaluation, the clone 'SP1456' of the North American species $P$. trichocarpa stands out due to its growth rate (Davel, 2011). Both are highly productive clones, the second with a better rooting ability (Zalesny and Zalesny, 2009). Regionally, the standard poplar planting stocks are stecklings, grown in bare-root nurseries for one year from small unrooted cuttings. Thus, cuttings stay at the nursery throughout one vegetative season, providing the opportunity to inoculate them, among other management practices.

Populus is one of the few genera known to form mixed mycorrhizal symbiosis, associating with ectomycorrhiza (EcM) and arbuscular mycorrhiza (AM) fungi. Mycorrhizal colonization has been proven to be essential for the development of most plants in production and natural habitat (Van Der Heijden and Horton, 2009). Mycorrhizal fungi are involved in processes such as transport, storage and exchange of nutrients, improving soil conditions, and maintaining the equilibrium of temperate forests (Smith and Read 2008), and they improve plant growth directly and indirectly by providing resistance to stress and in some cases to soil pathogens (Van Der Heijden and Horton, 2009). They also contribute to tolerating different stresses during production practices. Some microorganisms in the rhizosphere and mycorrhizosphere synthesize plant growth regulators and vitamins which facilitate the development and functioning of the mycorrhizal system in soil (Garbaye and Bowen, 1989; Barea et al., 2002), and they are considered "mycorrhizal helper microorganisms".

Soil microbial communities include prokaryotic and eukaryotic microorganisms with different ecological functions; some of them establish close relationships with plants and have great potential as plant growth promoters or biological control agents in plant production systems (Compant et al., 2010; Martin et al., 2016). Among the most commonly used benefic soil microorganisms are rizospheric and endophytic bacteria (Compant et al., 2010; Gupta et al., 2016). The presence of endophytic bacteria and symbiotic fungi in Populus spp. has been reported in native environments of the Northern Hemisphere (Doty et al., 2009; Taghavi et al., 2009; Xin et al., 2009). We have also confirmed the presence of endophytic bacteria and fungi in the bare-root nursery of P. nigra and $P$. trichocarpa at the INTA Experimental Station in Bariloche (Mestre et al. 2014a). Independently of their location and growth condition, these endophytic communities are very taxonomically diverse and they include species such as Pseudomonas, Stenotrophomonas, Enterobacter, Burkholderia, Bacillus (Doty et al., 2009; Taghavi et al., 2009). Some of these bacteria are able to perform a variety of functions related to plant growth promotion such 
as diazotrophy (Doty et al., 2009) or phytohormone production (Taghavi et al., 2009), and they were also studied as mycorrhizal helpers (Quoreshi and Khasa, 2008; Labbé et al., 2014). Yeasts have also been reported as part of the endophytic community of Populus trichocarpa in native environments (Xin et al., 2009).

In Andean Patagonia, Mestre et al. (2011; 2014b) described the presence of a large community of yeast in bulk-soil and rhizosphere from Nothofagus native forests, but the role of these yeasts is still poorly understood. Previous works with psychrotolerant yeasts strains (Aureobasidium pullullans, Holtermaniella takashimae, Tausonia pullulans, Candida saitoana and Candida maritima) from Patagonia suggest that they have physiological in-vitro features, which may positively influence plant growth (Mestre et al., 2016). From this study, native yeasts strains Tausonia pullulans CRUB 1772 (Basidiomycota) and Candida saitoana CRUB1770 (Ascomycota) were selected as good candidates to be used in plant trials, due to their abilities to produce auxinlike compounds and siderophores, to solubilize inorganic $\mathrm{P}$ and to inhibit the growth of Verticillium dhaliae and Pythium aphanideratum in co-culturing experiments (Mestre et al., 2016).

The aim of the present study was to assess the effect of mixed inoculation of mycorrhizae from native soil, the two native yeasts Tausonia pullulans CRUB 1772 (Basidiomycota) and Candida saitoana CRUB1770 (Ascomycota) and an endophytic bacteria isolated from roots of Nothofagus obliqua, on cutting growth traits of Populus nigra 'Italica' and Populus trichocarpa 'SP1456'. Our hypothesis is that the inoculation of native microorganisms on poplar unrooted cuttings increases growth and vigor of the resprouting shoots and favors the infection of mycorrhizae during rooting.

\section{Material and Methods}

\subsection{Greenhouse trial and plant material}

In September 2015, we installed two greenhouse trials (one trial per Populus clone) at the Experimental Station of INTA in San Carlos de Bariloche (41 ${ }^{\circ} 07^{\prime}$ S, $71^{\circ} 15^{\prime} \mathrm{W}, 810 \mathrm{~m}$ a.s.1.), using hardwood cuttings of Populus nigra 'Italica' and Populus trichocarpa 'SP1456'. We obtained the cuttings from a clonal bare-root stock growing at the same Station. All the cuttings were one-year-old, $30 \mathrm{~cm}$ long and $1 \mathrm{~cm}$ thick, and were collected at the end of winter and stored at 4 ${ }^{\circ} \mathrm{C}$ until planting. Prior to inoculation, we placed the cuttings into tap water for $72 \mathrm{~h}$ (water was refreshed every $24 \mathrm{~h}$ ). We planted each cutting in a 3-litre pot containing a mixture of sand, peat and soil from an undisturbed steppe site, in 1:1:2 proportion. Sand was washed twice with clean water and dried at $200{ }^{\circ} \mathrm{C}$, and peat was sterilized at $121{ }^{\circ} \mathrm{C}$ for $15 \mathrm{~min}$. We used the steppe soil as potential source of mycorrhiza and other natural populations of microorganisms. The pots were placed on a greenhouse table, in a completely randomized design with five replicates per inoculation treatment (see below), forming a group of 25 pots per clone, with one line of pots as bordure. Each pot had a translucent plastic crown surpassing the soil level by $10 \mathrm{~cm}$ to avoid cross-contamination due to splash during watering. Water was provided by micro sprinklers and adjusted according to temperature and plant needs, fluctuating between two or three times a week, one hour each time. We allowed the cuttings to grow for four months until budset at the end of summer. 


\subsection{Microorganisms and inoculation treatments}

Two selected yeasts and one bacterial isolate were used in the trial. The yeast Tausonia pullulans CRUB 1772 (Basidiomycota) was isolated from rhizospheric soil of Nothofagus pumilio. It produces auxin-like compounds $(3.68 \mathrm{ug} / \mathrm{mL})$ and is able to inhibit Verticillium dahliae PPRI5569 (30 \%) and Pythium aphanidermatum PPRI 9009 (17 \%) grown in coculturing experiments (Mestre et al. 2016). Candida saitoana CRUB1770 (Ascomycota) was isolated from bulk-soil in a Nothofagus antarctica forest. It produces siderophores (35.19\% yield), is able to solubilize inorganic P and to inhibit Verticillium dahliae PPRI5569 (25\%) and Pythium aphanidermatum PPRI 9009 (25 $\%)$ grown in co-culturing (Mestre et al., 2016). The bacterial strain was isolated from root-endosphere of Nothofagus obliqua seedlings growing in a greenhouse next to Populus bare-root stock. It was characterized as Gram negative cocci, is able to grow in $\mathrm{N}$-free media and to solubilize inorganic $\mathrm{P}$, and is a good producer of auxine-like compounds (unpublished).

Initial inoculation was done by submerging the base of the cuttings into four different suspensions of microorganisms and one control treatment, for $8 \mathrm{~h}$ prior to planting. We prepared Tausonia pullulans (T1) and Candida saitoana (T2) inocula by growing the yeasts in solid medium MYP (\% w/vol, malt extract 0.7 , yeast extract 0.05 , peptone 0.25 , agar 1.5 ) plates for $72 \mathrm{~h}$ at $20^{\circ} \mathrm{C}$. We prepared bacterial inoculum (T3) in a similar way, using medium TSA ( $\% \mathrm{w} / \mathrm{vol}$, tripteine 1.5 , soy peptone $0.5, \mathrm{NaCl} 0.5$, agar 1.5 ). Yeast and bacterial biomass were harvested and suspended in sterile $0.1 \mathrm{X}$ peptone-water $(\% \mathrm{~W} / \mathrm{V}$, soy peptone 1 , $\mathrm{NaCl} 0.5$ ) with added agar $0.1 \%$, at a concentration of ca. $10^{6}$ cell $/ \mathrm{mL}$. We prepared a mixture of the two yeasts and the bacteria to conform a fourth treatment (T4), using equal volumes of each suspension. The control treatment (T0) was performed by submerging the cuttings into un-inoculated peptone-water. Twenty days after planting, in coincidence with budburst, we applied a second inoculation by pouring $10 \mathrm{~mL}$ of each microorganism suspension ( $\mathrm{T} 1, \mathrm{~T} 2, \mathrm{~T} 3$ or $\mathrm{T} 4)$ or un-inoculated peptone water (T0), on each cutting at the soil level.

\subsection{Variables measured}

In February 2016, after the new shoots formed in all the rooted cuttings had closed their apical buds, we measured several growth traits. We counted the number of leaves of the three upper axes (NL) and the total number of roots (NR). We weighted the root $(\mathrm{Rdb})$ and shoot ( $\mathrm{Sdb}$ ) dry biomass (only the new tissue) with $0.001 \mathrm{~g}$ accuracy after drying at $90{ }^{\circ} \mathrm{C}$ for $5-7$ days; using these values we calculated total plant biomass $(\mathrm{Tdb})$ and their ratio as $\mathrm{R} / \mathrm{S}=\mathrm{Rdb} / \mathrm{Sdb}$. We removed and scanned six leaves from the largest sprouted shoot, two on each third, and with the software Hoja 3.4 (Verga 2010) we measured the average leaf area (ALA) of each plant ( $0.001 \mathrm{~cm}^{2}$ accuracy). As an indicatior of plant nutritional status, we measured a chlorophyll concentration proxy by Optical Density Difference at $660 \mathrm{~nm}$ vs. $940 \mathrm{~nm}$ (usually known as SPAD units) using Clorofilio ${ }^{\circledR}$ (Cavadevices).

We evaluated ectomycorrhizal colonization in fresh roots under stereoscopic microscope, looking for characteristic structures (Smith and Read, 2008b). Endomycorrhizal colonization was evaluated in thin roots collected and conserved in ethanol $70 \%$ until staining with Tryphan Blue (Phillips and Hayman, 1970). The occurrence and type of endomycorrhizal colonization and the occurrence of dark septate endophytes (DSE) were evaluated with an optic microscope Olympus BX40 (Smith and Read, 2008a). Arbuscular mycorrhizal (AM) colonization was considered positive when arbuscules were present (other structures such as coils and intra-radical and intracellular hyphae 
were also recorded). We calculated the percentage of colonization for endomycorrhiza (arbuscular mycorrhizal $=\% \mathrm{AM})$ and DSE (\%DSE) considering at least 300 fields (McGonigle et al., 1990).

\subsection{Data analysis}

First we revised the data (across treatments) for outliers, using the Dixon's Q-test, useful for small data sets. Then, we evaluated the effect of the inoculation treatments on all the traits measured on the rooted cuttings in each trial (i.e. by clone), with a one-way ANOVA model: ; $Y_{i j}=\mu+\alpha_{i}+\varepsilon_{i j}$ where $Y_{\mathrm{i} j}$ is a score for the experimental unit in treatment $a_{\mathrm{i}}$ and $\varepsilon_{\mathrm{i} j}$ is the experimental error NID $(0, \sigma 2 \varepsilon)$. We transformed the variables \%AM and $\% \mathrm{DSE}$ with the arcsin transformation to fit normality and homoscedasticity assumptions of the linear model (Zar 1999). Tukey's post-hoc tests were used to form homogenous groups when necessary. To assess the association between the root colonization (AM and DSE) and growth traits, we used Spearman's rank correlation. We performed the statistical analyses with Statistica 7 (StatSoft, Inc., 2007), except for the Dixon's $Q$-test that was performed with R (R Core Team 2016) package 'outliers' (Komsta 2011).

\section{Results}

\subsection{Plant performance}

Rooting and survival of cuttings was $100 \%$. The Dixon's Q-test for outliers showed that one plant from treatment T2 in P. trichocarpa had an extremely atypical DSE colonization value (\%DSE $=38.1 \%)$ $(\mathrm{Q}=0.53, p=0.003)$; therefore, we eliminated this plant from all the analyses. In Table 1 we show the overall means of the variables used to evaluate the performance of each clone. There was no correlation between both root colonization traits \%AM and \%DSE. In $P$. nigra, the \%DSE was negatively correlated with $\mathrm{Sdb}(r \mathrm{~S}=-0.52 ; p=0.007), \mathrm{Rdb}(r \mathrm{~S}=-0.43, p=0.034)$ and $\mathrm{NL}(r \mathrm{~S}=-0.45, p=0.0244)$. In $P$. trichocarpa, \%DSE was positively associated with the R/S ratio $(r \mathrm{~S}=0.52$, $p=0.0084)$ and $\mathrm{Rdb}(r \mathrm{~S}=0.50, p=0.0133)$; in contrast, AM was negatively associated with $\mathrm{Rdb}(r \mathrm{~S}=-0.48, p=$ 0.0182).

In $P$. nigra the root/shoot biomass ratio $\mathrm{R} / \mathrm{S}$ was significantly lower in plants inoculated with T. pullulans (T1) than in plants treated with the mixture of microorganisms $(\mathrm{T} 4 ; p=0.03)$ and un-inoculated plants (T0; $p=0.04$ ) (Figure 1). In P. trichocarpa the shoot dry biomass Sdb was higher in plants inoculated with Candida saitoana (T2) than in those inoculated with Tausonia pullulans (T1; $p=0.01)$ and un-inoculated plants $(\mathrm{T} 0 ; p=0.03)$. Although not significant differences were detected among treatments, $P$. trichocarpa showed marginal differences ( $p=0.06$ ) for total dry biomass, with higher values in plants inoculated with C. saitoana (T2).

\subsection{Mycorrhizal and endophytic colonization}

We did not observe ectomycorhizal colonization (EcM) on any plant. Instead, arbuscular mycorrhizal colonization was observed in all the plants with values ranging from $43 \%$ to $62 \%$ in $P$. nigra and from $50 \%$ to $69 \%$ in P. trichocarpa (Figure 2). Although no significant differences were detected among treatments, a tendency to higher \%AM colonization seems to occur in plants inoculated with T. pullulans (T1). Two morphologies of AM colonization could be identified: one with thick hyphae and another with thin hyphae and intercalary swelling (Figure 3). Dark septate endophytes were also observed but in low percentage (less than $5 \%$ ) in both clones. 
Table 1. ANOVA results on plant performance and colonization variables of two Populus clones.

\begin{tabular}{|c|c|c|c|c|c|c|}
\hline \multirow[b]{2}{*}{ Variable } & \multicolumn{3}{|c|}{ Populus nigra 'Italica' } & \multicolumn{3}{|c|}{ Populus trichocarpa 'SP1456' } \\
\hline & Mean & SD & p-value & Mean & SD & p-value \\
\hline \multicolumn{7}{|l|}{ Plant performance } \\
\hline Chlorophyll (SPAD) & 17.26 & 2.20 & 0.92 & 17.93 & 2.52 & 0.24 \\
\hline Shoot dry biomass (g) & 7.15 & 1.19 & 0.42 & 6.59 & 1.21 & $0.01 *$ \\
\hline Root dry biomass (g) & 1.56 & 0.40 & 0.15 & 3.07 & 0.81 & 0.53 \\
\hline Root/Shoot biomass & 0.22 & 0.04 & $0.02 *$ & 0.47 & 0.11 & 0.65 \\
\hline Total dry biomass (g) & 8.72 & 1.49 & 0.46 & 9.66 & 1.82 & 0.06 \\
\hline $\mathrm{N}^{\circ}$ of roots & 57.88 & 9.35 & 0.78 & 36.26 & 9.76 & 0.80 \\
\hline $\mathrm{N}^{\circ}$ of leaves & 70.64 & 8.23 & 0.57 & 42.46 & 6.29 & 0.41 \\
\hline Average leaf area $\left(\mathrm{cm}^{2}\right)$ & 7.29 & 0.89 & 0.81 & 16.91 & 2.99 & 0.40 \\
\hline \multicolumn{7}{|l|}{ Colonization } \\
\hline Arbuscular mycorrhizae (\%) & 51.28 & 12.94 & 0.18 & 59.38 & 13.76 & 0.07 \\
\hline Dark septate endophyte (\%) & 1.30 & 1.24 & 0.74 & 2.51 & 3.08 & 0.37 \\
\hline
\end{tabular}

"significant at the 0.05 probability level from analyses of variance (ANOVA)
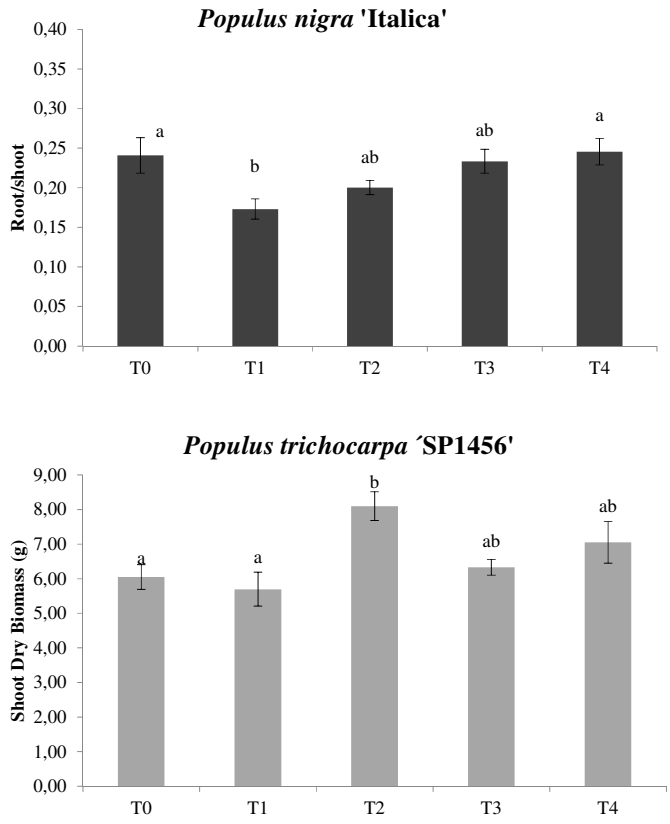

Figure 1. Shoot dry biomass production and Root/Shoot dry biomass rate on Populus clones. Whiskers correspond to standard error, and middle points to mean. Letters indicate different homogenous groups calculated by Tukey's post-hoc test.T1: inoculated with Tausonia pullulans, T2: Candida saitoana, T3: endophytic bacteria, T4: mixture of microorganisms and T0: un-inoculated plants. 

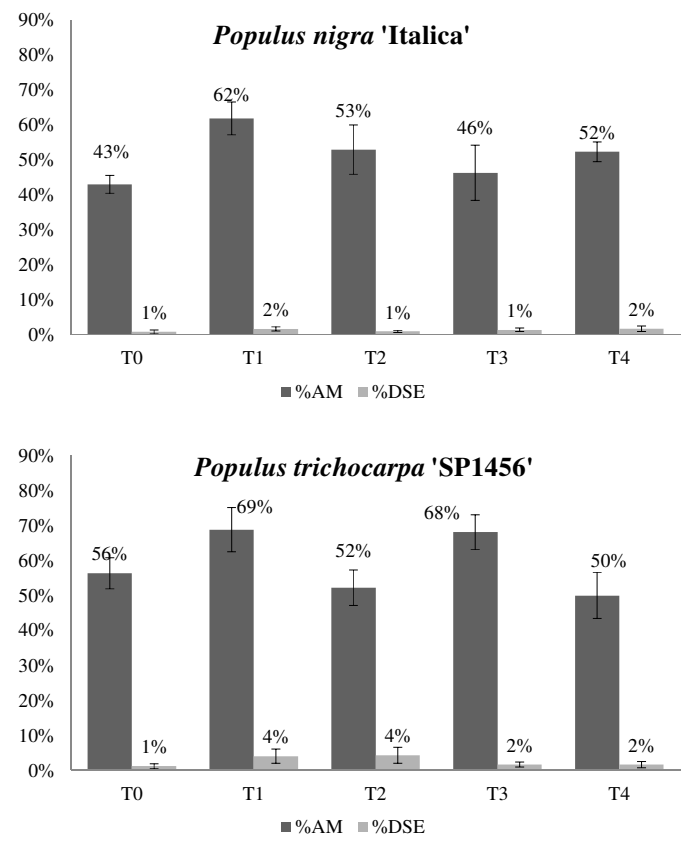

Figure 2. Percentage of colonization by arbuscular mycorrhizae (\%AM) and dark septate endophytes (\%DSE). Whiskers correspond to standard error, and middle points to mean. Letters indicate different homogenous groups calculated by Tukey's post-hoc test. T1: inoculated with Tausonia pullulans, T2: Candida saitoana, T3: endophytic bacteria, T4: mixture of microorganisms and T0: un-inoculated plants.

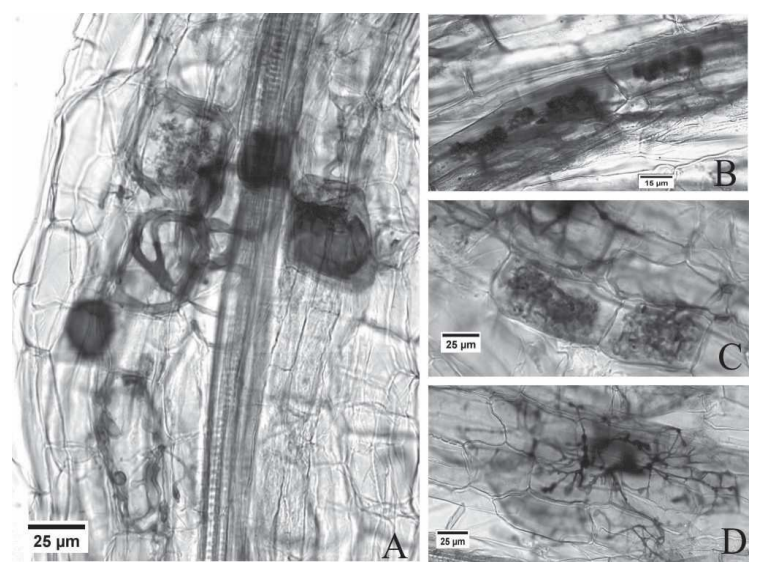

Figure 3. Mycorrhizal colonization on Populus roots inoculated with steppe soil. A) two types of mycorrhizal colonization; B) thick hyphae colonization arbuscules, C) thin hyphae colonization arbuscules; D) fan like colonization by thin hyphae colonization. 


\section{Discussion}

The survival, normal health and homogeneous nutritional status of all the plants in our trial showed that the inoculation with these yeasts and bacteria, separately or as a mixture (as well as the microbial community included in the native steppe soil), had no deleterious effects on the plants. The only exception could have been the plant we removed from the analyses due to its extremely high DSE colonization. Although we haven't found a clear explanation for this outlier, we observed that the whole plant was weaker in general (i.e. among the lowest in several growth traits) and even atypical (i.e. outlier) in other traits such as average leaf area $\left(\mathrm{ALA}=169.6 \mathrm{~cm}^{2}\right)$. But probably, the most interesting observation in this plant was that AM colonization was the lowest value $(\mathrm{AM}=10.9 \%)$ in the whole experiment (even much lower than in P. nigra), and this deserves attention in future research.

We observed only two clear responses in plant growth traits: R/S was lower in P. nigra when treated with $T$. pullulans (T1), while Sdb was higher in P. trichocarpa treated with $C$. saitoana (T2). Candida saitoana seemed to affect Tdb in P. trichocarpa (probably due to the increases in shoot dry biomass), although no significant differences among treatments were found. The inoculation of the endophytic bacteria alone (T3) or as a mixture with yeasts (T4), showed no-significant effects on any of the plant growth variables. Taghavi et al. (2009) had reported a host-related specific response in endophytic bacteria inoculation studies on Populus hybrids and Khan et al. (2012) had also reported similar host-related effects on other crop plants.

Tausonia pullulans, selected due to its ability to produce auxine-like compounds, reduced the $\mathrm{R} / \mathrm{S}$ ratio in P. nigra without having a negative effect over the other growth parameters. Lower R/S ratio possibly implies a higher intra- or inter-specific competitive ability, and the advantage of getting more shoot dry biomass per gram of root could be relevant in a later stage of production. Taghavi et al. (2009) have proposed that auxine production by endophytic bacteria inoculated in poplar cuttings are one of the mechanisms by which these bacteria increase tree growth. The inoculation of Candida saitoana improved shoot dry biomass production by $P$. trichocarpa in comparison with the un-inoculated treatment. This yeast had been selected due to its ability to produce siderophores and to solubilize inorganic $\mathrm{P}$; these features are directly associated with $\mathrm{Fe}$ and $\mathrm{P}$ acquisition by plants (Mestre et al., 2016). Increased nutrient access by plants is the most commonly proposed mechanism by which microorganisms promote plant growth (Compant et al., 2010; Hasan and Bano, 2015). Here we might infer $C$. saitoana improved nutrient access of our poplar cuttings, but this should be further studied. Plants of both Populus species presented arbuscular mycorrhizal colonization, but not ectomycorrhizal or any other type of mycorrhizal colonization. The absence of ectomycorrhizal colonization could be attributed either to the age of plants, the lack of inoculum, or low infective capacity in the trial system. Aguillon and Garbaye (1990) reported that Populus trees inoculated with both AM and EcM fungi had higher percentage of AM than EcM after 5 month of culturing, suggesting that early stages of growth favor AM colonization over EcM. Trees from the genus Nothofagus (Veblen et al. 1996), which are the unique ectomycorrhizal native trees, extensively dominate the Andean Patagonian forests. The Patagonian steppe vegetation near the forests, is principally colonized by arbuscular mycorrhizal fungi (Fontenla et al., 2001). As mycorrhizal inoculum, we used steppe soil, collected from a typical environment where poplar windbreaks are planted. Ectomycorrhizal plants associated with this environment are the native tree species Nothofagus antarctica and several planted exotic conifers (Pinus 
ponderosa, Pinus contorta and Pseudotsuga menziesii among the most common). Although a high degree of specificity between host and mycosymbiont is accepted, cosmopolitan EcM species Cenococcum geophilum was identified in both Nothofagus and Populus trees (Bahram et al 2011; Fernandez et al 2015). The absence of ectomycorrhizal trees near the soil collection site might support the lack of inoculum hypothesis. However, Fernández et al. (2013) showed that Nothofagus alpina seedlings produced in the same greenhouse of the present study were naturally colonized by EcM between 6 and 12 months after germination, without adding fungal inoculum. The authors suggest that seedlings were colonized by ectomycorrhizal fungi present in the cultivation system (i.e. culture tools, irrigation system, pots, etc.). The greenhouse was close to the Populus clonal bareroot stock, therefore similar mechanisms leading to $N$. alpina seedlings' natural colonization may have affected poplar seedlings. Several studies performed under greenhouse conditions using plant containers reveal that plants which are not inoculated have no EcM colonization (Neville et al., 2002). In the present study we cannot attribute the lack of EcM colonization to only one factor. Our results suggest that the external inoculation with specific EcM fungi could be a technological improvement on seedling production, in accordance with other authors (Aguillon and Garbaye, 1990; Neville et al., 2002; Quoreshi and Khasa, 2008). Two distinguishing types of AM colonization were observed, one formed by thick hyphae classically attributed to AM fungi and a second type formed by thin hyphae with intercalary swelling. We observed arbuscules formed by both types of colonization, but the thinner hyphae type had no vesicle. The morphological structure of this "thin hyphae colonization" is compatible with the Glomus tenue description. In 2016, Orchard et al. studied phylogenetic placement of this species and found that it is more closely related to Mucoromycotyna than to Glomeromycota. The author proposed revising the mycorrhizal status of this species and studying their interaction with plants and other AM forming fungi. Although it was not the aim of the present study to identify the mycorrhizae forming fungi present in Populus roots, it seems to be an interesting topic for future studies.

The negative association between \%DSE and dry biomass and number of leaves in P. nigra, suggests a negative effect of this colonization on plant growth. In P. trichocarpa the percentage of AM colonization was negatively associated with root biomass, but this did not result in diminished shoot biomass. It is possible that AM hyphae substitute roots for nutrient assimilation, but this deserves other specific research. Both Populus species showed an increase in arbuscular mycorrhizal colonization on plants inoculated with Tausonia pullulans, and in the case of P. trichocarpa the difference was marginally significant, thus supporting a probable tendency. The reduced $\mathrm{R} / \mathrm{S}$ ratio observed in P. nigra plants inoculated with T. pullulans could also be attributed to the higher mycorrhizal colonization since arbuscular mycorrhiza has been linked to enhanced acquisition and translocation of nutrients (Bonfante and Genre, 2010), so the same shoot dry biomass could be obtained with lower root biomass.

\section{Conclusions}

Pure yeasts were the only treatment which modified growth variables at significant levels, and it seemed to be a host-related specific response. The inclusion of soil from steppe with its natural microbiota allows for a simulation of the interaction of inoculated microorganisms with natural soil microbiota, which could be relevant for future field studies. Also, natural soil microbiota has no deleterious effect on plants suggesting the absence of pathogens. Mycorrhizal colonization was restricted to AM. The lack of EcM inoculum sug- 
gests the possibility to include EcM external inoculum as an advantage for the production of rooted cuttings in Patagonia, but it needs further investigation. In the present study, five-month old plants presented relatively high AM colonization using soil as inoculum source. Mycorrhizal inoculation using soil from natural environment appears as a potential advantage due to its low cost and the input of native AM strains which could be difficult to growth as axenic culture. We recognized yeast $T$. pullulans as a potential mycorrhiza-helper using soil as the inoculum source. Manipulation of mycorrhizal colonization, especially when using soil as an inoculum source, could be an important tool to enhance plant production. The present study showed the necessity for further investigation into the interaction of microorganisms native to Patagonia with exotic plants such as Populus spp., and showed encouraging results for their potential to improve poplar forestry.

\section{Acknowledgements}

The authors would like to thank the assistance of Lic. A. Carron, Dr. N. Fernández, M. E. Severino, Guide. J. Puga, Ing. Agr. P. Suarez, Mr. M. Huentu and Mr. F. Jaque, for their helpful assistance during technical and greenhouse works, and Dr. C. Bertoli for collaboration with micrographics. The present study was founded by UNComahue (project B170), PFIP-ESPRO Vinculado 2013, PIA 14081 and PICT 2014-1839.

\section{References}

Aguillon, R.L., Garbaye, J. 1990. Some aspects of a double symbiosis with ectomycorrhizal and VAM fungi. Agric. Ecosyst. Environ. 29, 263-266.

Barea, J.M., Azcón, R., Azcón-Aguilar, C. 2002. Mycorrhizosphere interactions to improve plant fitness and soil quality. A. van Leeuw. 81, 343-351.
Bahram, M., Pölme, S., Köljalg, U., Tedersoo, L. 2011. A single European aspen (Populus tremula) tree individual may potentially harbour dozens of Cenococcum geophilum ITS genotypes and hundreds of species of ectomycorrhizal fungi. FEMS Microbiol. Ecol. 75, 313-320.

Bonfante, P., Genre, A. 2010. Mechanisms underlying beneficial plant-fungus interactions in mycorrhizal symbiosis. Nat. Commun. 1, 48.

Compant, S., Clément, C., Sessitsch, A. 2010. Plant growth-promoting bacteria in the rhizo- and endosphere of plants: Their role, colonization, mechanisms involved and prospects for utilization. Soil. Biol. Biochem. 42, 669-678.

Davel, M. 2011 El cultivo de las Salicáceas en los valles irrigados de la Patagonia, pasado, presente y futuro. III Congreso Internacional de Salicáceas en Argentina.

Doty, S., Oakley, B., Xin, G., Kang, J., Singleton, G., Khan, Z., Vajzovic, A., Staley, J. 2009. Diazotrophic endophytes of native black cottonwood and willow. Symbiosis. 47, 23-33.

Fernández, N., Marchelli, P., Fontenla, S. 2013. Ectomycorrhizas Naturally Established in Nothofagus nervosa Seedlings Under Different Cultivation Practices in a Forest Nursery. Microb. Ecol. 66, 581-592.

Fernández, N.V., Marchelli, P., Gherghel, F., Kost, G., Fontenla, S.B. 2015. Ectomycorrhizal fungal communities in Nothofagus nervosa (Raulí): A comparison between domesticated and naturally established specimens in a native forest of Patagonia, Argentina. Fun. Ecol. 18, 36-47.

Fontenla, S., Puntieri, J., Ocampo, J.A. 2001. Mycorrhizal associations in the Patagonian steppe, Argentina. Plant Soil. 233, 13-29.

Garbaye, J., Bowen, G.D. 1989. Stimulation of ectomycorrhizal infection of Pinus radiata by some 
microorganisms associated with the mantle of ectomycorrhizas. New Phytol. 112, 383-388.

Gupta. H., Saini. R.V., Pagadala. V., Kumar. N., Sharma. D.K., Saini, A.K. 2016. Analysis of plant growth promoting potential of endophytes isolated from Echinacea purpurea and Lonicera japonica. J. Soil Sci. Plant Nutr. 16, 558-577

Hassan. T.U., Bano. A. 2015. The stimulatory effects of L-tryptophan and plant growth promoting rhizobacteria (PGPR) on soil health and physiology of wheat. J. Soil Sci. Plant Nutr. 15, 190-201

Khan, Z., Guelich, G., Phan, H., Redman, R., Doty, S. 2012. Bacterial and Yeast Endophytes from Poplar and Willow Promote Growth in Crop Plants and Grasses. ISRN Agronomy. 2012, 1-11.

Komsta, L. 2011. outliers: Tests for outliers. R package version 0.14. https://CRAN.R-project.org/ package $=$ outliers

Labbé, J.L., Weston, D.J., Dunkirk, N., Pelletier, D.A., Tuskan, G.A. 2014. Newly identified helper bacteria stimulate ectomycorrhizal formation in Populus. Front. Plant. Sci. 5.

Martin, F., Kohler, A., Murat, C., Veneault-Fourrey, C., Hibbett, D.S. 2016. Unearthing the roots of ectomycorrhizal symbioses. Nat. Rev. Micro. 14, 760-773.

McGonigle, T.P., Miller, M.H., Evans, D.G., Fairchild, G.L., Swan, J.A. 1990. A new method which gives an objective measure of colonization of roots by vesicular-arbuscular mycorrhizal fungi. New Phytol. 115, 495-501.

Mestre, M.C., Gentile, I., Pastorino, M., Fontenla, S. 2014a. Microrganismos endófitos radicales de Populus de relevancia en la producción forestal de Norpatagonia. IV Congreso Internacional de Salicáceas en Argentina.

Mestre, M.C., Fontenla, S.B., Rosa, C.A. 2014b. Ecology of cultivable yeasts in pristine forests in NorthPatagonia (Argentina) influenced by different en- vironmental factors. Canadian J. Microbiol. 60, 371-82

Mestre, M.C., Rosa, C., Libkind, D., Fontenla, S. 2011. Yeast communities associated with bulksoil, rhizosphere and ectomycorrhizosphere of a Nothofagus pumilio forest in Northwestern Patagonia, Argentina. FEMS Microbiol. Ecol. 78, 531-541

Mestre, M.C., Fontenla, S., Bruzone, M.C., Fernández, N.V., Dames, J. 2016. Detection of plant growth enhancing features in psychrotolerant yeasts from Patagonia (Argentina). J. Basic Microbiol. 56, 1098-1106.

Neville, J., Tessier, J.L., Morrison, I., Scarratt, J., Canning, B., Klironomos, J.N. 2002. Soil depth distribution of ecto- and arbuscular mycorrhizal fungi associated with Populus tremuloides within a 3-year-old boreal forest clear-cut. Appl. Soil Ecol. 19, 209-216.

Orchard, S., Hilton, S., Bending, G.D., Dickie, I.A., Standish, R.J., Gleeson, D.B., Jeffery, R.P., Powell, J.R., Walker, C., Bass, D., Monk, J., Simonin, A., Ryan, M.H. 2017. Fine endophytes (Glomиs tenue) are related to Mucoromycotina, not Glomeromycota. New Phytol. 213, 481-486.

Phillips, J.M., Hayman, D.S. 1970. Improved procedures for clearing roots and staining parasitic and vesicular-arbuscular mycorrhizal fungi for rapid assessment of infection. T. Brit. Mycol. Society. 55, 158-161.

Quoreshi, A.M., Khasa, D.P. 2008. Effectiveness of mycorrhizal inoculation in the nursery on root colonization, growth, and nutrient uptake of aspen and balsam poplar. Biomass Bioenerg. 32, 381-391.

Serventi, N. 2011. Las cortinas forestales en los valles irrigados de la Norpatagonia. III Congreso Internacional de Salicáceas en Argentina. 
Serventi, N., García, J. 2004. Situación actual y perspectivas futuras de las salicáceas bajo riego de Cuyo y Patagonia. SAGPyA Forestal. 32, 24-27

Smith, S.E., Read, D. 2008. Mycorrhizal Symbiosis (Third Edition). Academic Press, London, pp. 42-90.

Taghavi, S., Garafola, C., Monchy, S., Newman, L., Hoffman, A., Weyens, N., Barac, T., Vangronsveld, J., van der Lelie, D. 2009. Genome Survey and Characterization of Endophytic Bacteria Exhibiting a Beneficial Effect on Growth and Development of Poplar Trees. Appl. Environ. Microbiol. 75, 748-757.

Van Der Heijden, M.G.A., Horton, T.R. 2009. Socialism in soil? The importance of mycorrhizal fungal networks for facilitation in natural ecosystems. J. Ecol. 97, 1139-1150.

Veblen, T.T., Hill, R.S., Read, J. 1996. The ecology and biogeography of Nothofagus forests. New Haven: University of Yale Press, 414p.
Xin, G., Glawe, D., Doty, S.L. 2009. Characterization of three endophytic, indole-3-acetic acid-producing yeasts occurring in Populus trees. Mycol. Res. 113, 973-980.

Zalesny, Jr, R.S., Zalesny, J.A. 2009. Selecting Populus with different adventitious root types for environmental benefits, fiber, and energy. In: Niemi K., C. Scagel (eds). Adventitious Root Formation of Forest Trees and Horticultural Plants- From Genes to Applications. Chapter 18. Research Signpost. 359-384.

Zar, J. 1999. Biostatistical Analysis. Fourth Ed., Prentice Hall, NJ, 663 p. 